eundo, and which prevents recovery so long as the circle continues in operation. This does not mean that recovery is impossible in the ordinary course of events. For nnaided Nature can, and often does, succeed in breaking the circle, although her methods may be slow and the result only partially satisfactory. For example, the circles associated with a nasal polypus or an aural cholesteatoma, as described above, may be snapped by the expulsion of the irritation mass. A sharp epistaxis may relieve the engorged mucosa which is associated with so many correlations. Even a nasal sinusitis may be cured by Nature. But broadly speaking, the i is medicatrix nature does not often succeed in breaking the circle; her efforts need usually to be supplemented by those of art.

By evacuating a tympanic cavity that is distended with pus, by the removal of a goitre that is compressing the trachea, by inflating an obstructed Eustachian tube, the ars medioa accomplishes cito, tuto et juounde what Nature unaided could only accomplish clumsily and imperfectly if at all. Even drugs may render great service, as for instance when a single insuffation of gr. 1/20 of morphia cures a laryngeal cough that has persisted for weeks, or as when a blocked antrum of Highmore or a naso-frontal duct is cleared by a strong solution of cocaine which allows the escape of the imprisoned pus. A full dose of bromide may arrest an otalgia that was perpetuating the circle of insomnia and neurasthenia. One signal advantage derived from the recognition of a circle is that, since there are at least two factors concerned, there must be at least two points open to attack, two points at which a breach can be effected. A careful consideration will guide the practitioner as to the best strategy. In some cases the morbid process will readily yield if the lomus minoris resistentice is attacked. At other times each of the reciprocally acting factors must be dealt with. Thus the study of the circle conduces to a broad insight into disease and renders treatment more scientific, more philosophical, and more successful.

Reading.

\section{THE VITAL PHENOMENA OCCURRING UNDER ANÆSTHESIA-}

NERVOUS, CIRCULATORY, RESPIRATORY, AND METABOLIO-AND THEIR RELATION TO THE SAFETY OF THE PATIENT. ${ }^{3}$

BY DUDLEY WILMOT BUXTON, M.D., B.S. LOND, M.R.C.P. LOND.,

ADMINISTRATOR AND IECTUREE ON AN-ESTHETICS, UNIVERSITY COLLEGE HOSPITAI AND ROYAL DENTAI HOSPITAL, ETC.

IT is necessary, in setting before this society the facts and arguments involved in my subject, that I should point out the essential differences which exist in the requirements of modern surgery from those demanded a few decades ago.

Anæsthesia, or the loss of all sensation and perception of pain, was regarded as the end aimed at by the use of such drugs as chloroform, ether, and so on. This end obtained, the administration ceased; if the time required, and this seldom exceeded a few minutes, was not covered by the administration, the drug was again and again inhaled. The records of the earlier days of anæsthesia reveal that automatic and subconscious movements, protective spastic contractions of muscles over painful areas, were disregarded. The patient was relieved of pain, and for the rest it did not matter. The French surgeon Péan speaks with pleasure of his etherised patients being able to converse. The surgeon of to-day demands not only this anæesthesia, but a degree of narcosis which lessens reflex action throughout the body and controls to a profound degree the processes of life.

It is often overlooked that anæsthesia is a definite point in narcosis; a patient feels or he cannot perceive pain, there can be no light anæsthesia nor deep anæsthesia; what is termed light is not anæsthesia if pain is perceived as pain, and increase of the drug's effect beyond bare anæesthesia is deep narcosis, not deep anæsthesia. Terminological exactitude is essential to the appreciation of the points under discussion. Further, the surgery of to-day of necessity requires that the patient should remain in narcosis for a prolonged period, possibly for two or three hours, and the very

\footnotetext{
1 A paper read before the Medical Society of London on April 22nd.
}

nature of the operations often necessitates the gravest interference with large areas of highly organised tissues. Surgical shock at the time of operation and its aftermath, delayed recovery, may occur. The skill and courage of the modern surgeon do not fail even when the general condition of the patient before an operation is undertaken is extremely unfavourable, and so the patient starting with heavy handicaps of disease and exhaustion against him has to contend with a prolonged anæsthesia as well as with the depression consequent upon a severe trauma.

Accepting the inevitable results of surgery, we turn to consider what is involved in the process of the induction of anæsthesia, and what in that of the maintenance of a more or less profound narcosis.

The induction period is the obvious danger zone, and has, therefore, received the greatest amount of attention. Whatever drug is employed a series of changes in the normal processes of life have to be effected. Progressive abolition of the function of the nerve centres leads from excitation to un consciousness, and may lead later to enfeeblement of respiration and ultimately to circulatory standstill. This is easily recognised, and is, therefore, common knowledge, but the causation of the changes is as yet uncertainly appreviated, while various opinions, often in conflict, have been advanced to explain the facts as presented before us.

We are, however, concerned with those processes which supervene from the point when anæsthesia is present until such time as the patient has emerged from the immediate effects of the operation as well as from those of the narcotic. These may be the direct results of what has taken place during the induction period or may be something superadded, or, indeed, conceivably they may arise sui generis daring a period of profound narcosis.

The work of Hans Meyer, Overton, and more recently of Moore, Roaf, and others, appears to indicate that certain anæsthetics enter the tissues by forming "aggregations" with the protoplasm of tissues. We are probably justified in believing that the red corpuscles convey the anæsthetic to the cells, which in their aggregate form the tissues. The blood itself becomes influenced and shares in the general effects produced. There is definite evidence that nerve tissue, muscular tissue, and the cells of glands are profoundly sensitive to at least some of the narcotics. The effects produced vary according to the amount and concentration of the anæsthetic introduced into the blood stream, but further, tissues possess individual susceptibility. Thus a certain concentration will excite function, while a further concentration will lead to diminution or even to abeyance of function. As to individual susceptibility, the muscular fibres of the myocardium are readily affected by quantities of a narcotic, or more accurately, a degree of concentration of a narcotic, which will produce little or no apparent effect upon voluntary muscular fibre, while the nervous tissue reveals itself as being one of the most responsive of structures to this influence. Nerve tissues, again, appear to react differently according to their degree of organisation. We also know that although the varions anæsthetics induce kindred effects, apparently by similar paths, yet they reveal individual differences in their reaction towards individual tissues. A further point of great importance is that the blood, together with the other tissues of the body, is capable of taking, or may we say aggregating, more of the anæsthetic than will produce mere diminution of function.

If we are justified in putting together the results of a large number of isolated researches, we have presented to us a connected picture of what happens when an ancesthetic is given in a certain bigh concentration for a brief time, or for a prolonged period at $\mathbf{a}$ lower but uniform concentration. At first some variation of function of all the tissues occurring in a definite order progressively from the most to the least sensitive tissues; then diminution of function in the like order; and later loss of power to functionate in those tissues most easily affected, followed by a similar result throughout the organism nntil the processes of life cease to be performed. Ultimately there occurs tissue death. This then represents what is always tending to take place during deep narcosis while all the vital fanctions are undergoing progressive depreciation. We exclude catastrophic annihilation, since this when due to the anæsthetic arises as a result of overdosage, either absolute or relative, and nsually during the period of induction.

It is clear, however, that the effect of an anæsthetic by 
lowering the vitality of tissues or lessening the capacity for work, more especially of those which are not component parts of those systems which have been happily termed the tripod of life, may lead to such profound interference with function as eventually to destroy life, and it may be at some considerable time after the gross effects of the drug have been dissipated. On the other hand, experiments have shown that the physical aggregation between an anæstbetic and the protoplasm of a living cell is reversible. When the tension of the anæsthetic is higher in the stream which environs the cell it becomes aggregated to the protoplasm of the cell, while, when the internal tension exceeds the external, then the protoplasm at once parts with the excess of the anæsthetic which becomes eliminated.

The questions are thus forced upon us, does this effect produced on the tissue, if prolonged beyond a certain point, merely lower the vitality of the protoplasm or result in any condition other than mere abeyance of biochemical processes? How far do diseased conditions of the organism affect the reaction of the protoplasm of the living cell towards the invading material, the anæsthetic? Unfortunately there is very little available information upon these points which can be accepted as conclusive. Theories, nnless based upon reliable experimental research, are of slight value, and the researches, such as they are, lack in one essential condition - they do not sufficiently differentiate between conditions which are the outcome of quantilies of an anæsthetic which induce anæsthesia, and of those which are toxic rather than therapeutic.

Thus McWilliam, whose work is of great value, speaks of percentages of chloroform of 4 to 4.5 per cent. as being within the limits of routine anæsthesia, and describes the results of such concentrations, althongh ever since the time of Snow (1858) toxic effects have been recognised as occurring whenever the strength of vapour of chloroform exceeds 2 in the 100 .

Inhalation of ether has been shown by Offergeld to produce definite changes in the epithelium of the lungs, but that this is not a necessary result is amply shown both by experiment and by clinical experience. The blood is affected by all known aræsthetics, and the changes produced become of grave import when patients are suffering from blood diseases, themselves associated with poorness of bæmoglobin and abnormal proportion of the blood cells. Da Oosta pointed ont, as indeed did Harley, although the latter relied upon experiments in vitro, that hæmolysis may arise after inhaling chloroform or ether. Intravenous ether infusion causes hæmatinuria when a certain strength is employed.

Some years ago I investigated the question of hæmolysis following inhalation, attempting to eliminate the effects of hæmorrhage, starvation, operative shock, and asphyxial condicions, and found that judged by blood count it was impossible within a limited number of cases to arrive at any definite conclusion. The proportion of coloured cells was frequently diminished, but not uniformly so. One found that a series of cases in which oxygen was freely used gave normal blood counts, while immediately afterwards another series gave an abnormal count. Nor were the environing conditions different so far as one could ascertain. It is doubtless true, and experiment reveals and supports the fact, that anæs. thetics when allowed to exert toxic influences react destructively upon the blood. The evidence is not conclusive, but it appears probable that the activity of the blood cells, like that of the cells of the tissues, suffers diminution.

Although Tissot asserted that the hæmoglobin of the corpuscles could aggregate oxygen so long as systemic life persisted, his statement seems in the light of later research to be open to modification. It must appear, then, that degrees of narcosis in which the blood becomes burdened more and more by an anæsthetic may, when prolonged, cause damage to the blood and so interfere with the vitality of the tissues. Graham ${ }^{2}$ indeed asserts that in the case of rabbits - probably also, he contends, in that of man-ether when inbaled lessens phagocytosis as regards the pneumococcus, the streptococcus, and the staphylococcus. It is his view that the phagocytes are themselves damaged, while no serum change takes place, and he hazards the theory that the solvency of ether as regards fatty material explains this action. At the same time, he admits that bacteriolysis and agglutination are unaffected by ether.
The experimental work which has been done upon nerve and muscle is too well known to need more than formulating in the following statements. Nerve tissue at first reveals variations in its reaction to stimulation, later loses its excitability. Nerve centre cells have been shown to undergo structural modification.

Muscular tissue, according to the strength of the anæsthetic perfusing its vessels, loses its contractility, and in the case of the myocardium may pass into paralytic dilatation. Marked effects have been produced experimentally and observed on post-mortem examination, in the case of glandular structures, and especially in that of the kidneys and liver. We are probably safe in believing that most of the secretions are materially affected in narcosis, and as function is changed so also is the structure of the epithelium modified, often in a deleterious sense. What we do not at present know is within what limits these effects may be produced without permanent injury accruing to the tissues affected.

Panl Bert found that prolonged inhalation of very weak chloroform vapour, too dilute to induce anæsthesia in the case of dogs, resulted in death, and he explained this fact by the theory that the anæsthetic killed by profoundly affecting the metabolism of the animal. Taken by itself Bert's view may not carry conviction, but the researches of Thiem, Fischer, Ungar, Strassburg, and many since their time, have given it much corroboration, since they demonstrate that repeated inhalation of the anæsthetic leads to death, and that the death results from fatty changes in the liver and other organs such as we accept to be due to perversion of metabolism.

Destruction of the epithelial cells of the kidneys and derangement of the renal function bave been again and again advanced as proof of the danger of anæsthetics. In a research undertaken (1890) by me with the assistance of Dr. Levy it was stated: "The fact is, there is little evidence tending to show that ether exerts directly any deleterious influence on the kidney parenchyma. The albumin found in the urine of the dogs which had undergone experiments, we believe, is not to be explained in this way, but by the indirect action of the anæsthetic, in that it produces, when pushed to an excessive dose, an ischæmia of the kidney, that is, the specific ether effect."

But the problem we are considering is not circumscribed by a mere inquiry into the direct or indirect effect of the anæsthetic apon individual tissues, or, indeed, upon the organs; if it were so, we could obtain the data for its solution by experiments of a comparatively simple character. In dealing with the intact organism we cannot disregard that intimate effects arise which are produced by interference with the physiological form of respiration, of circulation, and, above all, by the interference with the physiological control by the nervous system. Unhappily, when we anæsthetise our patient we are not able to switch off nerve reaction.

Without attaching too much importance to Dr. Orile's picturesque way of explaining his views upon surgical shock, I may avail myself of his forceful description. Shock, then, means the result upon the nervous centres of a bombardment of sensory impulses which, even although they are not stereotyped into a perception of pain, yet produce that effect which means nerve exhaustion. That anæsthetics may, and probably do, produce some nerve blocking is not open for me to discuss at present; I am only concerned in asking you to remember that under a surgical operation the patient's life has to be maintained in spite of the direct effects of anrsthetics upon the cells of the organism, and in spite of an abnormal controlling central nervous system.

It may be urged that I have proved too much or too little. Wither that no surgeon ought to undertake a serious opera tion when the patient is under a general anæsthetic, or that the experiences of countless successful operations so performed prove the futility of the contention I have ventured to advance-namely, that during narcosis tissue life is subject to peculiar dangers, such as must be reckoned with in counting the cost to life.

It was the fond hope of the pioneers of such modern methods as local infusion of analgesics, spinal analgesia and regional analgesia that with the employment of such methods had come the surgical millennium. Unhappily, the pæan had hardly been sung when the fact was forced upon us that man, under the waking exercise of his nervous system, snffers shook even more perilons in some cases than that induced by dragging upon and cutting the tissues of an 
unconscious patient. That psychic shock exists we cannot afford to doubt. We know a brave man will fall in a dead faint when an anral speculum is used, and death has followed the prick of a hypodermic needle. I cannot, however, elaborate this portion of the subject.

That surgical operations nnder general anæsthesia can be carried out safely, although pbagocytosis is abolished and tissues are bathed in a narcotic fluid and the central nerve control is abnormal, is quite true. It is so because the dangers to which I have referred have been averted, not because they are visionary. This fact constitutes the capital contention of my essay.

There is sufficient evidence, I submit, that tissue changes, probably of a deleterious nature, can and do occur during narcosis, the cause being the sum of the effects produced by the anæsthetic, together with the trauma, or insult to tissue ; that, further, derangements of the nerve-control mechanisms affecting metabolism, trophic conditions, respiration, circulation, and excretion coincidently occur, and these again arise through the summation of the effects of trauma and the anæsthetic. These changes vary within very wide limits-at times are very slight and so escape observation, at times severe, calling for grave attention and remedial measures.

In many cases a further factor exists-the condition of the patient. If he is free from some pathological lesion his vitality may be depressed by such conditions as prolonged fasting, exposure or antecedent trauma, as in the case of railway smashes and in that of women with flooding at the menopause. Otherwise the patient may be crippled by serious organic disease. The existence of one of these factors makes for increased damage during a prolonged narcosis.

Now the dominating fact brought out by the study of the anæsthetic's share in producing prejudicial results is that all anæsthetics act progressively and proportionately to their strength in solution. Tnat they possess individual peculiarities is patent, so that while one may exhaust by depression, another may do so by prolonged over-stimulation; one may ultimately destroy by poisoning protoplasm, while another may only destroy by wearing down the resistance of the exhausted nerve controls. But these by-issues must be left for later analysis. The reason, then, why serious damage is not evident in all cases is shown by one of two facts. Either the individual patient may be able to expel an excess of the narcotic, or else measures may be adopted on the one hand to prevent increasing the effects on the tissues of the anæsthetic, and on the other to prevent undue depression of tissue by trauma. But to adopt such measures it is obvious we must realise the necessity for them, and this we can only do by recognising tissue interaction with narcotics.

It is impossible in the time at my disposal to enter into detail with regard to protective measures. From the side of surgery, it may be said that most surgeons recognise the importance of minimising damage to the nervous system caused by rough handling and exposure of viscera and peritoneal structures, and so they frequently perform operations in two stages and adopt other measures to effect this object. In all cases which are not of emergency a prolonged and careful preparation is possible. The regulation of diet should replace the starvation regimen which is so dangerous, although Dr. Gundrum's research ${ }^{3}$ appears to discount in some degree the effect of starvation in the case of healthy anicals. Avoidance of starvation is important, however, when patients are feeble.

If we review the large amount of work which has now been carried out concerning post-operative glycosuria and the germane condition of acidosis, we find that while many patients after inhaling anæsthetics develop acidosis, not a few give evidence of this condition after changes of dieting, af'ter purgation or alteration in their environment, and without having taken an anæsthetic at all. That acidosis may be engendered by anæsthetics Whipple, Sperry, and others have shown. The central necrosis of the liver lobules is, however, a toxic effect, and it is doubtful whether it arises tbrough the instrumentality of the anæsthetic in cases in which therapeutic quantities of a narcotic have been employed. Nor must it be forgotten that, unless respiration is failing and so elimination is at fault, it is less the gross amount of an anæsthetic which is harmful, than the concentration in which it is allowed to flood the tissues.
I will only mention without elaboration the importance of the selection of the type of anesthetic and the method of its use, a selection controlled, first by the exigencies of the patient's condition, and secondly by the dominating claims of the surgeon. Even a judicious choice of the agent may be shown to have been unfortunate in the progress of the narcosis, and such a possibility must always be held in mind, so that a change of anæstbetic or modification of method may be made at any period. The use of some preliminary drugs, such as morphine and scopolamine, undoubtedly protects the patient in two ways-it lessens psychic disturbance and diminishes the quantity of a general anæsthetic required during the narcosis.

Assuming there are no definite signs of unusual happenings during a narcosis, beyond the obvious effects of prom longed inhibition of physiological processes and the slowly developing phenomena of shock, the inhalation if kept at the same level will deepen narcosis, and if the anæsthetic is a stimulant such as ether the initial stimulation of the nervous system will give place to an ever-increasiog exhaustion. If the anæsthetic is a depressant, such as chloroform, its maintenance at the same level of strength will gradually replace depression of function by profound exhaustion. Ever so slight a failure of respiration leads to lessened pulmonary ventilation, and this to diminished oxidation, until with falling blood pressure and imperfect oxidation of the blood the tissues throughout the organism become enfeebled, if not rendered moribund

This vicious circle easily escapes observation until duskiness and lessened hæmorrhage enforce attention. But beyond what has been indicated we have to reckon with the increased toxicity of the anæsthetic if it is permitted to be inhaled by a patient who has passed into this degree of narcosis. The output of the anrsthetic is lessened, and its tension in the tissues becomes steadily increased. To obviate such a condition-and its occurrence is far more common than you may believe-it is requisite to obtain that degree of narcosis which the surgeon needs, and for so long as it is needed, and then to lessen the strength or concentration of the anæsthetic until the output equals the intake or slightly exceeds it. The experienced anæsthetist can gauge this with accuracy. As the shock increases, the netd for the anæsthetic lessens. Since we recognise that shock means loss of temperature, falling blood pressure, and lessened oxidation, we adopt the classic remedies, warming the table, depressing the head, and supplying warmed oxygen to counteract these effects. Dr. Willcox has found in extreme cases passing oxygen through alcohol to be of value, but I think any measures of stimulation other than those of saline infusion and the application of heat are sources of danger. I am convinced that much of the shock following operations is dne to exhaustion resulting from excessive stimulation.

The key to the whole situation lies in the recognition that very little of any anæsthetic is needed to keep up any level of narcosis when the level is once established, and that so long as the tissues are not over-narcotised the cells will by their inherent vitality part with the aræsthetic, reverse the aggregation, and so regain their normal physiological state.

Even in artificially produced acidosis the cells of the hepatic lobules which have undergone necrosis have been shown to recuperate, but this can only occur when the general vitality of the organism has not been excessively depressed. Indeed, this has been shown experimentally to be true of other, mainly epithelial, tissues; so that there is every pre. sumption in favour of the belief that when a narcosis is maintained without excessive interacticn between the narcotising agent and the tissues of the body, such tissues even if temporarily damaged will rapidly recover, provided their requirements-e.g., adequate blood-supply and so onare safeguarded and physiological conditions are promptly reinstated.

Mortimer.street, W.

The Crownhill Convalescent Home, near PLYMIOUTH. - The twenty-nirth annual meeting of the frien is of the Crownhill Convalescent Home was held on May 3rd. The medical report stated that during 1911 the patients admitted numbered 319 , and by far the larger number of these derived great benefit from the "clear and bracing air of Dartmoor." The financial statement showed that an unfavourable balance of $£ 62$ remaired at the close of the year. 